\title{
Discussion on RFID and Food Cold Chain Logistics
}

\author{
Yingxin Liu ${ }^{1, a}$, Wei Shi ${ }^{2, b}$ \\ ${ }^{1}$ Shenyang University Information Engineering Institute, China \\ ${ }^{2}$ Shenyang Technician Institute, China \\ ayingxin888@126.com, shiwei365@163.com
}

\section{Keywords: RFID; Frozen food; Cold chain; Tag}

Abstract. Along with the rapid development of national economy and the increasing of life level day by day, people have a new understanding on frozen and chilled foods. At the same time food safety problems have also been paid attention. RFID is a new type automatic identification technology with good function characteristic, which can satisfy efficiency requirements of commodity processing, and it has many advantages compared with the bar code and can strictly control food quality in cold-chain logistics to promote healthy development of cold chain logistics.

\section{Introduction}

Along with the rapid development of national economy, the increasing of life level day by day, and the tempo of modern society speeding up, people have a new understanding on frozen and chilled foods. In recent years, food industry pays more and more attention to it as the cold chain industry develops dramatically. But many food issues also seriously threaten the safety of consumers, as well as healthy and stable development of food industry.

From March 1, 2010, China formally implements GB/T24617-2009 national standards of "frozen food logistics packaging, mark, transportation and storage", made clear the concept of food cold chain. Food cold chain is a logistics state under low temperature and must always keep low temperature in the production, packaging, transportation, storage, sales and other links, so temperature can produce very big effect on the quality of the products. Currently cold chain includes primary agricultural products-vegetables, fruit, meat, poultry and eggs, aquatic products, flowers; processing products-frozen food, poultry and meat, aquatic products and other packaging cooked food, ice cream and dairy products, fast food raw material; special commodity-drugs.

\section{The Problems of Food Cold Chain Logistics}

\section{Not Enough Refrigerating Transportation Equipments.}

According to a set of data from China Traffic Yearbook in 2009, railway cold storage traffic volume in China was only occupied $25 \%$ of the perishable cargo traffic volume, less than $1 \%$ of the total amount of railway transportation; Railway refrigerator cars had 7492 cars, accounting for $1.34 \%$ of the running vehicles, and most vehicles were mechanical quick-frozen vehicles and refrigerated trucks adding ice that had been eliminated abroad. According to incomplete statistics, national total railway running vehicles were 338000 cars, only 6970 cars for refrigerator, accounting for just $2 \%$, lacking of insurance refrigeration trunks with regulating heat preservation. Cold storage traffic accounted for only $25 \%$ of the volume of perishable goods, less than $1 \%$ of railway freight transport. China had 30000 vehicles with heat preservation, but the United States has 200000 cars, and Japan has 120000 cars. Freight ratio of refrigerator vehicles is only $0.3 \%$. Also transportation rate in the United States, Japan and western European countries is up to $80 \%-90 \%$, while in China only about $10 \%[1]$.

Insufficient Utilization of Refrigeration Houses. The data from cold storage branch of China storage association basically is the statistics of cold storages above 500 tons. It includes part of cold storages that can be sure it being there, but can't determine its operations. Part of the owners open the cold storage today and close it tomorrow for savings cost, just as "three days of fishing, two days of drying net"[2]. For enterprises, to build the cold storages is to make a profit, but too loose examine and approval causes non-standard construction of a few cold storages, and management is not strict. 
Imperfect Standards of Cold Chain. As we all know, there are hundreds of frozen food, and they need different temperature, so technical indicators about each product such as low temperature storage control time are also different. For example, fresh milk and yogurt need keep 4-7 centigrade, fruit and vegetables keep 10-15 centigrade, and quick-frozen food below 0 centigrade, etc. But at present the various standards including systematic technical standards, loss and efficiency standards, best operations standards of cold chain, safety standard, environment temperature and temperature control standard have not yet come on[3]. There is no a binding standard in the cold chain logistics for reference in China, only some large food enterprises establishes some standards, but the supervision is blank.

The Shortage of Logistics Technology. Cold chain technology is system engineering under low temperature with high technology, developing on the basis of food processing technology and refrigeration technology, involving in food safety. Freezing technology and processing ways of classification and grading, packaging and processing under low temperatures have not been popular, and temperature control means during transport process is also primitive extensive way, although automatic control equipment of the whole process has widely used in developed countries, China has no widely used it.

Backward Third Party Logistics Enterprises. There are some small and medium-sized enterprises engaging in cold chain logistics in China, whose strength is weak with small scale, and service standards are inconsistent. But large scale cold chain logistics enterprises equipped with the abilities of resources integration and promoting industry are just at an initial stage. In domestic circulation, most manufacturers and distributors would complete the distribution of perishable food by themselves, for the third party cold chain logistics enterprises develops lags, service network and information system are not enough sound, and cold chain cost and commodity consumption are very high.

\section{About RFID}

Radio Frequency Identification (Radio Frequency Identification, RFID), commonly known as electronic tag, is a non-contact automatic identification technology and automatic identify objects and obtain relevant data through the radio-frequency signal. It brings revolutionary impact to logistics and retail industry. The RFID system generally consists of four parts, namely, electronic tag, reader, RFID middleware and application system software[4].

Working principle of RFID system, as shown in Figure 1:

- Reader can send some radio frequency signal with fixed frequency through the antenna;

- The tag will produce induced current when it enters into launching area, and tag is active with energy, and send its own coding information to reader;

- After receiving carrier signal, reader will demodulate and decode, then send to information network system for processing;

- The system will identify the information with logo coded, and handle the requirements according to system, so as to achieve the item management and monitoring.

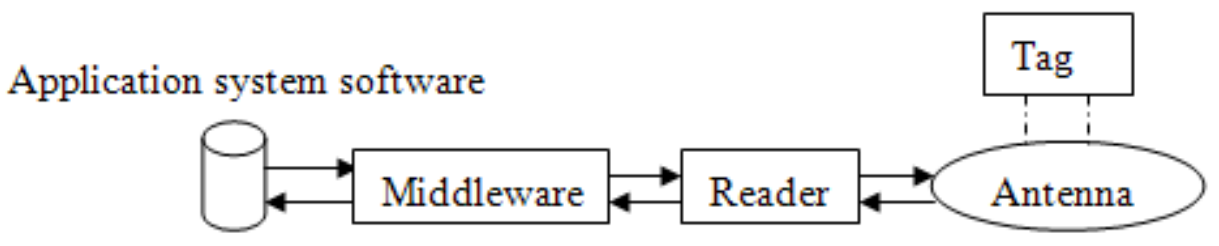

Fig. 1 RFID system

The characteristics of RFID in the supply chain context - that it can be read unattended, in groupings of various sizes, through some materials and with a level of flexibility regarding orientation and positioning between tag and reader-creates the possibility that RFID use will become transformational. Rather than simply substituting for existing technologies such as bar codes within current processes, it holds the promise of process innovations that create orders of magnitude improvements in supply chain business models[5]. 


\section{RFID Application in Food Cold Chain}

- At first, source enterprises use RFID tags on food or raw materials, including some basic information, such as production area, production date, storage method and edible method.

- When frozen-foods from origin arrive at food manufacturers, processing plant will store information into the tag for next processors or consumers.

- Inspection agencies supervise and administer quality, and the information and warehouse information are also put into the tag.

- Distribution centers send the foods with RFID tag to local agencies, to the supermarkets, restaurants and fast food restaurants, then the information in the stage is witten to the the tags. In each link above, all information about foods during the supply chain can be written into RFID tag, which like a interlocked chain and form the complete information about the food at last, so as to improve food retrospective mechanism and ensure food safety.

- Finally, people eat food at the dinner table.

\section{The Advantages of RFID in Food Cold Chain Logistics}

\section{Tracking Cold Chain Logistics and Increasing the Transparency of Food Management.}

The core of RFID technology is EPC on the label, that is, Electronic Product Code. EPC can track goods in the whole cold chain logistics due to unique identification of physical objects. Using RFID technology, food can be tracked timely and accurate from the start of production in the supply chain to be kept transparent.

Simplifying Operation Process and Improving Efficiency. The characteristics of refrigerated and frozen food decide the operation be simplified as much as possible and shorten the time. So RFID tags are pasted in trays and boxes, and reader is installed at the exit/entrance of distribution center, so without manual operation, which can meet information scanning requirement when the goods outgoing and incoming warehouse with forklift trucks and can identify multiple tags dynamically for long distances one time. So it will save time in out/in warehousing and increase work efficiency.

Reduced Shortage and timely Replenishing. For retailers, when automatic replenishment system shows that they need the replenishment, they can order goods from the upstream enterprise immediately. So using RFID technology can ensure food security and arrive in time, and can not be short of stock.

\section{Summary}

Applying RFID in food cold-chain logistics can greatly reduce the cost, improve management level of enterprises, decrease damage of food, better solve food security problem, and ensure the quality of food. RFID will be a vast range of application prospect.

\section{References}

[1] The National Logistics Standardization Technical Committee: China Packaging Industry Vol. 10 (2010), p. 74-76

[2] Liu Longchang: China Co-Operation Economy Vol. 8 (2010), p.12-13

[3] Zhang Ge: Science Technology Information Development \& Economy Vol. 19 (2009), p. $128-130$

[4] PAN Fubin: Logistics and Procurement Research Vol. 32 (2009), p. 42-45

[5] Richard Mathieu, Fred Niederman, Roger Morley and Ik-Whan Kwon: Communications of the ACM Vol. 7 (2007), p. 93-101 